\title{
The family practice of support-giving after a pediatric cancer diagnosis: a multi-family member interview analysis
}

\author{
Marieke Van Schoors ${ }^{\mathrm{a}}$, M.D.; Jan De Mol ${ }^{\mathrm{b}}, \mathrm{PhD}$; Lesley L. Verhofstadt ${ }^{\mathrm{a}}, \mathrm{PhD}$; Liesbet Goubert ${ }^{\mathrm{a}}, \mathrm{PhD} \&$ \\ Hanna Van Parys, $\mathrm{PhD}^{\mathrm{c}}$ \\ ${ }^{a}$ Department of Experimental Clinical and Health Psychology, \\ Ghent University, Ghent, Belgium \\ marieke.vanschoors@ugent.be; lesley.verhofstadt@ugent.be $\&$ liesbet.goubert@ugent.be \\ ${ }^{\mathrm{b}}$ Department of Clinical Psychology \\ Université Catholic de Louvain, Louvain-la-Neuve, Belgium \\ jan.demol@uclouvain.be \\ ${ }^{c}$ Department of Psychiatry \\ Ghent University Hospital, Ghent, Belgium \\ $\underline{\text { hanna.vanparys@uzgent.be }}$
}

Address correspondence to:

Marieke Van Schoors, Department of Experimental Clinical and Health Psychology,

Ghent University, H. Dunantlaan 2, B-9000 Ghent, Belgium

Tel: $+32-9-264.86 .11$ - Fax: $+32-9-264.64 .89$.

E-mail: marieke.vanschoors@ugent.be 
Note: This is an uncorrected version of an author's manuscript accepted for publication. Copyediting, typesetting, and review of the resulting proofs will be undertaken on this manuscript before final publication. During production and pre-press, errors may be discovered that could affect the content. 


\begin{abstract}
Purpose: Pediatric cancer presents many challenges to the life of the child diagnosed with cancer and his/her family. Among the studies investigating risk and protective factors, social support has emerged as an important construct. However, little is known on how family members support each other in this particular context.
\end{abstract}

Method: In order to further explore this process, interviews were performed separately with mothers, fathers and siblings. Multi Family Member Interview Analysis was used as a methodological framework to analyze the individual interviews, allowing a detailed and systematic analysis of shared family experiences.

Results: The analysis of the data revealed three themes: Being together matters: the families identified the need of being physically together; Finding support in (not) talking: the complexity of sharing emotions was explained and Working together as a team: the families described working together as a team in order to get everything organized.

Conclusions: This study broadens our understanding of the interpersonal process of family support-giving when facing pediatric cancer. When meeting with families, families should be invited as a unit in order to best capture family level experiences. Also, clinicians should be sensitive to the different cancer-related communication needs within the family (i.e., the need to talk or not to talk) and incorporate this knowledge into their care.

Keywords: Children, Cancer, Families, Support, Qualitative research, Interview 


\section{Introduction}

Pediatric cancer is an unpredictable and uncontrollable stressor for the diagnosed child and his/her family members. There are a number of pediatric cancers, with blood cancer, including leukemia (30\%) and lymphoma (8\%), as the most common type (American Cancer Society, 2016). Current pediatric cancer treatments are very intensive, including hospitalization, painful and invasive procedures, surgery, chemotherapy, and/or radiation therapy (Alderfer et al., 2009). The impact of the illness and its treatment on the physical and psychological wellbeing of all family members is therefore undeniable.

There is a growing body of literature on the psychological adjustment of families dealing with pediatric cancer. In the current literature, it is concluded that a significant subset of patients, parents and siblings are at risk of adjustment difficulties. For example, some children with cancer experience social or emotional problems during (Kestler \& LoBiondo-Wood, 2012) or after treatment (Kazak et al., 2001). In addition, feelings of uncertainty, anxiety, depression and posttraumatic stress symptoms can be observed in parents of children with cancer shortly after diagnosis (Vrijmoet-Wiersma et al., 2008). Similarly, some siblings show elevated levels of post-traumatic stress symptoms, negative emotions or report poor quality of life when compared to siblings of healthy children (Alderfer et al., 2010; Long et al., 2018). It should be noted, however, that the research described above also revealed considerable variability, across and within studies, in individual outcomes for children being confronted with pediatric cancer and their family members. More specifically, some children and family members seem to adjust better than others.

Given this great variability of outcomes, a growing number of researchers have tried to explore why this is the case. Among the studies investigating detrimental and protective factors influencing the adjustment of families being confronted with pediatric cancer, social support has emerged as an important construct (Alderfer \& Hodges, 2010). Moreover, as children are embedded in a family (Carr, 2012; Fiese, 1997) and the family is an important social support system for children and adolescents (e.g., Newman et al., 2007), the importance of family support in the context of pediatric cancer has frequently been emphasized. Indeed, according to several empirical studies (e.g., Alderfer \& Hodges, 2010; Varni et al., 
1994; Zegaczewski et al., 2015) and a recent meta-analysis (Van Schoors et al., 2017) greater perceived family support is associated with better child adjustment, for both the diagnosed child and their siblings.

Notwithstanding the growing body of evidence emphasizing the importance of family support in the context of pediatric oncology, little is known onhow exactly family members support each other after a pediatric cancer diagnosis. A qualitative interview study was therefore set up to allow an in-depth exploration of the specific ways in which family members support each other when facing pediatric cancer. Furthermore, the concept of family support was assessed from the perspectives of multiple family members. Existing qualitative studies on (the importance of) family support typically make use of a single family member as the informant (Van Schoors et al., 2015). Because the unit of interest (i.e., support at the family level) should harmonize with the unit of measurement (Weber, 2011), we argue that studies with only a single informant do not adequately capture support within the family.

To fill this gap, we completed a study using one-to-one interviews with multiple family members (i.e., mothers, fathers and siblings), focusing on family support-giving. Multi Family Member Interview Analysis (MFMIA; Van Parys et al., 2017) was used as a methodological framework to analyze the individual interviews, focusing on families as the unit of analysis. Inspired by Interpretative Phenomenological Analysis (Smith et al., 2009) and Dyadic Interview Analysis (Eisikovits \& Koren, 2010), MFMIA allows a detailed and systematic analysis of shared family experiences (Van Parys et al., 2017). This approach has proved insightful in studies that analyze experiences shared by family members, particularly when assessing sensitive topics such as adjustment to an illness (Eisikovits \& Koren, 2010). The research question that guided our interviews and data-analysis was 'How exactly do family members support each other when facing a pediatric cancer diagnosis?'.

\section{Method}

\section{Participants}


The present study is part of a larger ongoing study in Flanders (Belgium), examining the impact of a pediatric cancer diagnosis on families. Using a purposive sampling strategy, children diagnosed with leukemia or non-Hodgkin lymphoma between the age of one and eighteen, their parents and any siblings were invited to take part in a longitudinal survey. Exclusion criteria were: 1) not speaking Dutch, 2) expression of a developmental disorder in the diagnosed child and 3) relapse. All participating parents ( $\mathrm{N}$ $=173$ individuals, including 55 couples $)$ and siblings, aged between 10 and $16(\mathrm{~N}=27)$, were subsequently invited to complete an interview about their experiences regarding the influence of the cancer diagnosis on their family life. Thirty-three couples (60\%) and 15 siblings (56\%) agreed to participate in this interview study. Ten couples and ten siblings were then randomly selected and contacted by the first author. Ten mothers, ten fathers and ten siblings were interviewed separately. For the purpose of this study, only data from the four families in which both parents and at least one sibling participated were analyzed as this allowed for an analysis at the family level. Table 1 shows the participating families' characteristics. Data-collection was done by two onco-psychologists under the supervision of the last author (HVP) who is specialized in family interview techniques. Approval of the Ethics Committee of the University Hospitals of Ghent, Brussels, Antwerp and Louvain was obtained, both for the longitudinal survey and the interview study. All participants received written and verbal information about the study. Confidentiality was assured during all phases of the study. 
Table I. Families' characteristics

\begin{tabular}{|c|c|c|c|c|c|c|c|c|c|c|c|c|c|}
\hline Family & $\mathrm{Name}^{\mathrm{DC}}$ & $\mathrm{Age}^{\mathrm{DC}}$ & Gender $^{\mathrm{DC}}$ & Diagnosis $^{\text {DC }}$ & TSD & $\mathrm{Age}^{\mathrm{M}}$ & $\mathrm{Age}^{\mathrm{F}}$ & $\begin{array}{l}\text { Marital } \\
\text { Status }\end{array}$ & $\#^{\text {kids }}$ & $\mathrm{Age}^{\mathrm{S} 1}$ & Gender $^{\mathrm{S} 1}$ & $\mathrm{Age}^{\mathrm{S} 2}$ & Gender $^{\mathrm{S} 2}$ \\
\hline & Daisy & 16 & Female & CML & 5 & 48 & $49 *$ & Divorced & 3 & 16 & Female & - & - \\
\hline & Lien & 16 & Female & Non-Hod & 5 & 45 & 44 & Married & 3 & 15 & Female & 14 & Male \\
\hline & Bob & 4 & Male & ALL & 26 & 38 & 37 & Married & 3 & 11 & Female & - & - \\
\hline & Ruben & 8 & Male & ALL & 24 & 42 & 44 & Married & 2 & 10 & Male & - & - \\
\hline
\end{tabular}

Note . $\mathrm{DC}=$ diagnosed child; $\mathrm{TSD}=$ time since diagnosis (months); $\mathrm{M}=$ mother; $\mathrm{F}=$ father; $*$ = non-participating father; $\mathrm{S} 1=$ first participating sibling; S2 = second participating sibling; $\mathrm{CML}=$ Chronic Myeloid Leukemia; Non-Hod = non-Hodgkin lymphoma ; ALL = Acute Lymphoblastic Leukemia

\section{Data collection}

Interviews took place at the participants' homes. Parents gave their written informed consent at the time of the interview. For the sibling interviews, written informed consent of both parents and assent of the child were obtained.

Participants' (parents and siblings) interviews consisted of questions about their experiences of the diagnostic and treatment process and their perspectives on their family relationships and family functioning post-diagnosis (Table 2; detailed interview guide available upon request). All family members were interviewed separately as this allowed them to share their own perspective on the research topic without having to take into account the feelings of other people in the room (Morris, 2001). Parent interviews lasted between 59 and 143 minutes; sibling interviews lasted between 40 and 107 minutes. Each interview was audio-taped and transcribed verbatim using pseudonyms. 
Table 2: Family Interview questions

Parent interview

Sibling interview

To what extent did the disease affect your family?

How did you as a family experience/endure this period?

What has changed in your family due to this diagnosis/illness?

To what extent was there an influence on your relationship with your children?

How would you describe social support within the family?
How has the disease affected your family?

What changed in your family when your brother/sister became ill?

To what extent could you talk about the disease with your parents? With your brother/sister?

How did this period affect your relationship with your parents? Or with your brother/sister?

How did you experience the support within your family?

\section{Qualitative Analysis}

Inspired by Interpretative Phenomenological Analysis (IPA; Smith et al., 2009) and Dyadic Interview Analysis (Eisikovits \& Koren, 2010), Multi Family Member Interview Analysis (MFMIA; Van Parys et al., 2017) facilitates the understanding of broader family dynamics by obtaining and combining the perspectives of multiple family members. MFMIA consists of three phases (Fig. 1; for a more in depth description of this method, see Van Parys et al., 2017, p. 395). In the first phase, the interviews were analyzed separately, which included (a) adding initial notes based on interview observations and theoretical concepts to each transcript, (b) line-by-line coding based on the research question ("how do family members support each other exactly when facing a pediatric cancer diagnosis?'), (c) clustering of the codes (e.g., "it seems important for this father to accompany the ill child to the hospital) into higher level themes (e.g., being physically together is important) and (d) writing up a narrative/summary for each of the interviews. The second phase consisted of a within-family analysis: themes of the interviews with the mother, father and sibling(s) of one family were combined in a theme structure for the family. In a third phase, we searched for parallel themes between the different families. Thus, the final list of main themes and subthemes reflects patterns of convergence between the different families, whilst doing justice to divergences and unique outcomes as well. The merit of this approach lies in the focus on the family 
level: by first doing the MFMI-analysis within the families, and then across the families, we are able to say something about what typifies families, rather than what typifies mothers, fathers or siblings.

To enhance the trustworthiness of the study, a team of auditors (listed here as co-authors) was invited to challenge the way the first author constructed themes and subthemes at several points in the analysis (Hill et al., 1997). Based on extensive research reports, these auditors verified whether the analysis had been conducted systematically and transparently, and whether the research report was credible (Smith et al. 2009). More specifically, the first auditor (last author; HVP) is specialized in family interview techniques and qualitative data-analytic methods, and was the principal investigator's academic mentor. The second author (JDM) functioned as the second auditor and notably contributed to the construction of emergent themes at a theoretical and conceptual level.

\section{Results}

Analysis of the data on the family practice of support-giving after a pediatric cancer diagnosis could be clustered into three main themes. Specifically, in the first theme, the families identified the need of being physically together, both as a family and with the diagnosed child. The second theme articulated the eagerness of the families to talk about the illness and its impact, as this was experienced as a relief. However, talking about emotions was sometimes also experienced as hard and some family members preferred not sharing these experiences. In the third theme, the families described working together as a team in order to get everything organized (see Fig. 2).

\section{Being together matters}

The families in our studies indicated that they felt supported by each other's presence. They identified a need of being physically together as one family unit, and they ensured that always (at least) one of them accompanied the diagnosed child to the hospital, regardless of the child's age.

\section{1a. Feeling strengthened by being physically together}


From the moment of the cancer diagnosis onwards, the families in our study felt separated: the diagnosed child and one or both parent(s) stayed at the hospital, whereas the siblings stayed at home or were taken care of by others.

When Lien had to go to the hospital, our family was torn apart. When Lien came back, we were reunited. So yeah, it really felt like 'we're back together again'. (Sibling, 16 year)

As a consequence, for most families, the moments they were all together were scarce and thus were appreciated more. They enjoyed spending time as one family.

I liked it when we all watched a movie together, or when we went out for a picknic, or when my brother, my dad and I were playing football together. It never lasted long, but it was really cool and then my mother would watch us with a smile. (Sibling, 10 year)

In addition, the importance of physical contact in order to cope with the cancer experience was emphasized. Parents and siblings gave hugs to express their love and to comfort each other.

Every day there were hugs. The children cuddled each other, just as we cuddled the children, and I hugged my wife. (Father)

Similarly, a mother in another family described that embracing the ill child was all she could do, as words and other attempts to help were often insufficient.

If your sixteen year old daughter that cries constantly...The only thing you can do is take her into your arms and lay down in the bed together with her. (Mother)

It seemed that parents and children tried to support each other by being physically together: by their presence, they showed companionship, availability and emotional support.

\section{1b. Never leaving the diagnosed child alone}


The parents in our study ensured that one of them always accompanied the diagnosed child to the hospital and that the ill child was never left alone.

Bob has never been by himself. [He was] either with me or my wife. (Father)

Regardless of the age of the diagnosed child, accompanying the ill child during the hospital stays was deemed important by the parents of all four families. The parents indicated that the cancer treatment was too severe for the child to endure alone.

When you have a child with cancer, even when this child is sixteen years old, you don't leave her alone. She wouldn't have been able to. It was too heavy. (Mother)

In addition, the siblings also tried to visit their ill brother or sister as much as possible.

Yeah, I visited her quite often. There is no other way right, cause she's my sister. (Sibling, 14 year)

For this sibling, visiting his ill sister showed that he was concerned about her health and wanted to help her with his presence. Parents accompanied the diagnosed child day and night and never let that child alone, but this was different for the siblings. They reported having a need to continue their daily life as well, and searched for a balance between supporting their ill brother/sister, attending school and maintaining their own social life.

I didn't feel like, I mean, maybe that sounds a little selfish: 'I will visit Lien often but I won't be there every day'. (Sibling, 15 year)

Finally, in one family, the mother considered the implications of going out as a family while the diagnosed child was at the hospital. Taking into account fatalistic scenarios, this family decided to never leave the diagnosed child alone and therefore never went on a trip with just the siblings.

My father wanted the four of us (parents and two siblings) to go to an amusement park one day. But I really didn't feel like it, just the idea, maybe it sounds strange, but imagine that something happens to the four of 
us, that we have an accident, then he [diagnosed child] would stay behind alone. I just couldn't think of that. Let's say, I didn't want that. (Mother)

\section{Finding support in talking and not talking}

Most families in our study found it important to talk about the cancer experience, and perceived this talking as a relief. However, for some family members, talking about this emotional experience was not easy, and therefore not talking was preferred. This theme shows the complexity of communication about the pediatric cancer diagnosis and treatment within families.

\section{2a. Talking as a relief}

The families in our study found it important to talk about the illness and its consequences.

We kept on talking to each other. And that's really important, that's really really important. (Father)

Moreover, talking about the cancer diagnosis was perceived as helpful in coping with the experience. For one sibling, this was even the most helpful thing in coping with his brother's illness.

Interviewer: What do you think helped you the most?

Sibling (10 year): Uhm, talking about it with my family.

It seems that family members in particular understood each other's worries and fears, and that, therefore, family members appreciated each other's help more than help from outsiders.

It's still odd when I talk about it or when I hear about it (cries). I also told my wife. I couldn't think of anyone else I would have been able to overcome this period with. So I must kiss both my hands that I have a fantastic wife and two fantastic children. (Father)

In addition, talking about the cancer and its consequences was also perceived as a relief. In one family, this was described by both the mother and the sibling. 
I think that's always been a strength of my husband and me, that both of us are people that talk. Neither of us bottle up. That's how we always did things, and it really helped us this time. (Mother)

Sometimes we also had talks about the illness in the hospital room or something, how it was going with my brother and that was a relief, when we had a talk like that. (Sibling, 10 year)

For this family, being able to talk about the cancer experience was described as one of their family's strengths. And although this strength was already present pre-diagnosis, it became even more pronounced post-diagnosis.

\section{2b. The complexity of sharing emotions}

Although all of the families in our study talked about the cancer, in every family, communication seemed to have its own characteristics and challenges. For example, in one family, parents and siblings found it hard to talk about emotions, instead talking about the medical details of the cancer and its treatment.

We did talk about the illness, but let's say, not about feelings or anything. (Mother)

Interviewer: Were you able to talk about the illness with your parents?

Sibling (11 year): Yes, when I had questions, I was. But apart from that, well, there used to be questions like 'how did it go' and things like that, but apart from that, we didn't talk about it a lot.

The complexity of sharing emotions was also experienced by another family. The father described the concern that sharing his worries could elicit worries in the other family members.

What I'm also afraid of is, when I touch upon that fear or emotion, that I will elicit it in somebody else as well. When I tell you [the interviewer] that this fear is huge, then it doesn't induce fear in you. As an outsider, you can listen to it. If I would say it to my wife or the children or to Lien, then I kind of create, I guess, the same fear and emotion in them. (Father)

This quote is illustrative of the ambivalence often reported by families facing pediatric cancer. More specifically, it may be considered necessary to talk about the cancer in order to cope with the experience 
and even helpful or preferable by parents and children. However, at the same time, when a family talks about the cancer, it is not only about receiving support from one another, but also about taking into account the emotions elicited by such conversations. Family members do not want to upset each other and, therefore, sometimes rather prefer not to share these experiences within the family, but talk with friends or clinicians. After all, as the diagnosed child is a shared loved one, all family members share the same fear of losing that child. This fear of death, the commonality of this fear and how difficult it was to share was expressed by the following father:

It's really hard to express this in the family. One kind of hides it a little bit. It's a really difficult period. Sometimes you protect yourself and the others by not naming or discussing the very anxious things, even though they are there. Everybody struggles with it. (Father)

It seemed that talking about death and loss only occurred when the actual possibility of death became real. The families only talked about these intense emotions when, as a whole, they could no longer hide behind the hope and conviction the ill child would heal.

At the beginning Lien caught an infection of which we didn't know the cause. She had an almost forty degree fever and then it came really close. Then you do have to talk about it. It's only in moments like that, that you cannot get around it anymore. Those are really heavy emotions. (Father)

\section{2c. Keeping silent instead}

Every family had its own way of coping with the cancer experience. For some, sharing might have been a relief (cfr. 3.1). However, others preferred not to talk about the cancer or the emotions evoked by such an intrusive situation.

Interviewer: Could you talk about Lien's illness to your mum and dad?

Sibling (15 years): Uhm, actually I didn't do that a lot. 
Furthermore, in some families, differences in preferred coping style occurred between family members and these differences (i.e., talking vs. not talking) were sometimes hard to handle.

My husband and I were very different. Emotions were very hard for him. Very hard. For me that was less of a struggle. That [the difference] was not easy. (Mother)

In addition, even in families who were used to sharing their daily stresses, the cancer situation sometimes forced them not to talk, as they were too tired or too emotional at that time.

One of our principles used to be: 'when there's something between the two of us, or something that's on our mind, whether it's legitimate or not, we won't go to sleep before we talk things through'. And yeah, that rule, we had to drop it now and then because we were just too tired, both physically and mentally. Yeah, then you feel like: 'we cannot do this right now, let's get back to it tomorrow'. (Father)

The complexity of giving words to emotions was also described by other families. In this respect, it seemed that the more families struggled to find words, the more they found solace in the physical proximity of the other family members (see also subtheme 1a "Being together matters").

\section{Working together as a team}

The families in our study described working together as a team, to get everything organized. More specifically, due to the many hospital stays and the unpredictability of the illness, family members were forced to re-think their contribution to the family life and to make new arrangements. This was described by the father and the sibling of one family.

Before, I almost never went grocery shopping, then [post-diagnosis] I went a lot more. I did bit more of this, then I vacuum cleaned... But that's obvious, right, when she [his wife] was in the hospital. (Father)

I didn't have much time off; we had to help more with things at home, cause otherwise you didn't manage alone. (Sibling, 11 year) 
This family described the self-evidence of helping more in the household, as the mother was mostly in the hospital accompanying the diagnosed child. Indeed, whereas pre-diagnosis, the family members seemed to have clear and distinct roles and expectations of each other, they started to work more together as a team from the diagnosis onwards.

Well, my wife was there, and I was here. Things had to move on. Then you vacuum cleaned sometimes, and you did this, and you went to the shop so there was food. Teamwork is what we call it. She put things in the dishwasher and the washing machine and I hung the clothes to dry and emptied the dishwasher. (Father)

In addition, as parents indicated they were both responsible for the care of the diagnosed child and the financial situation of the family, parents divided all the work and made arrangements to accomplish both tasks.

Because women are often mums, they're better at caregiving. And because they're better at it, and we notice that they do it well, that's a reassurance. Not that I ever worried about it. That's a reassurance. That's why you leave it to your partner. The advantage is that I could empty a part of my hard disk. The fact that I could outsource this care completely to my wife, enabled me to function 'normally' in my job. (Father)

According to this father it was by working together that the family as a whole was able to get everything organized. Moreover, only by dividing the family tasks the individual family members were able to manage, and to keep their head up in these difficult times.

\section{Discussion}

When a child is treated for cancer, the lives of all family members change. In order to best cope with this stressful situation, family support has been put forward as an important resource (e.g., Zegaczewski et al., 2015). In the present study, we used a phenomenological-hermeneutic research method to interpret the narratives from the parents' and siblings' interviews in order to gain a better understanding of the specific ways in which family members support each other when facing pediatric cancer. This qualitative method was chosen with the aim of capturing the lived experiences of families regarding the processes of family 
support-giving in the context of pediatric oncology. Multi-family member interview analysis was used to integrate the perspectives of the different family members within one family, before moving on to the convergences across families, allowing agreement between the unit of interest (family level of support) and the unit of analysis.

Three themes emerged from the analysis. In the first main theme, Being together matters, parents and siblings indicated that they felt supported by each other's presence. This is in line with previous qualitative studies (e.g., Brody \& Simmons, 2007; Sloper, 2000), a recent systematic review (Van Schoors et al., 2015) and meta-analysis (Van Schoors et al., 2017), illustrating that family support helps families to cope with cancer. In addition, this study contributes to the current body of evidence by emphasizing the importance of being physically together: by their presence, the participants in our study showed availability and emotional support, as being together was sometimes all they could do to help the other.

The second main theme, Finding support in talking and not talking, illustrates the need to share cancer related experiences within the family, emphasizing the idea of 'social sharing of emotions': people who experience an intense emotion describe an imperious need to share this experience and to talk about it (Rimé, 2009). Moreover, parents and siblings in this study perceived talking about the illness as helpful and as a relief. This is in line with previous qualitative studies (e.g., Prchal \& Landolt, 2012) and a metaanalysis showing that greater expressivity within the family is associated with better child adjustment (Van Schoors et al., 2017). However, talking about emotions was not always perceived as easy and sometimes not talking was preferred. This illustrates the complexity of family communication postdiagnosis. Indeed, although a family member may have felt the desire or need to talk about the cancer experience, they only shared their experiences when the other was perceived as emotionally strong enough and fully available. This study adds to the current body of research that, regarding the possibility of losing the diagnosed child, families sometimes perceived it easier to talk with strangers (i.e., friends, clinicians) than with family members, because sharing these intense emotions of threatening loss could elicit the 
same negative emotions in the others. In other words, due the fear to elicit painful thoughts and feelings in the others, family members sometimes decided to keep silent instead of sharing.

In the third main theme, Working together as a team, family members were forced to rethink their contributions to family life. They felt they needed to work together even better than pre-diagnosis; a finding that has also been found in previous qualitative studies (e.g., Prchal \& Landolt, 2012; Van Schoors et al., 2018).

Taken together, we aimed to address two specific gaps in existing research. First, we focused on how family members supported each other after a pediatric cancer diagnosis. Second, using MFMIA, we were able to produce family level interpretations from the individual interviews, integrating the perspectives of multiple family members and creating a multi-faceted understanding of family support in the context of pediatric cancer.

\section{Methodological Considerations}

Some limitations in the current study need to be addressed. First, the number of included families $(\mathrm{N}=4)$ was small, which could elicit questions of transferability. However, like all qualitative studies, we did not aim to achieve generalizable findings, instead aiming to get a better understanding of specific family processes using a specific sample in a specific context. Second, the present study is part of a largescale project. As a consequence, the number of included families was fixed and the principle of data saturation (i.e., reaching a point in the analysis that sampling more data will not lead to more information related to the research question) could not be applied. Third, our sample consisted ofBelgian, Caucasian families. It is likely, however, that the experiences of families in other countries or with other nationalities differ. Fourth, we did not include the perspective of the ill child. This was due to the fact that the diagnosed child already participated to the longitudinal survey study, and we did not want to fatigue the ill child. Discrepancies in perceptions across family members (Alderfer et al., 2009; Stegenga et al., 2018), however, speak to the need to collect data from all involved individuals. For example, by including the 
diagnosed child, the reciprocity of family support could have been investigated in more detail and/or other ways of support giving could have been identified. As a consequence, to best capture family level constructs such as family support, the perspectives of all family members should be taken into account. Fifth, interpretations may be challenged by language differences: while the interviews were conducted in Dutch, the results were written in English. Sixth, in order to assure network confidentiality, the dissemination of our results had to be at a general level, rather than at a family level (Ummel \& Achille, 2016). In other words, the strength of this analysis (being able to offer an in-depth understanding of shared family experiences) at the same time encompasses the method's main shortcoming: we simply cannot exemplify all new insights at a family level when seriously considering our responsibility as researchers to protect (family) confidentiality.

To address these limitations, future research should further explore the idea of family support using the principles of data saturation and incorporate the perspectives of all family members (diagnosed child, mother, father, siblings), in heterogeneous families and heterogeneous cultures/countries.

\section{Implications for Nursing Practice}

The findings of this study may help clinicians to better understand how families adapt after a pediatric cancer diagnosis. Three specific recommendations can be put forward. First, when dealing with pediatric cancer, clinicians should offer to meet the family as a whole. Only by taking into account the perspectives of all family members, experiences at a family level could be understood. Second, as families indicated that they felt supported by each other's presence, efforts should be made to sustain this physical togetherness. For example, the parental desire to accompany the diagnosed child in the hospital around the clock (Van Schoors et al., 2018) illustrates the importance of hospitals providing (the possibility of) rooming in and flexible visiting hours for siblings. Third, clinicians working with families affected by pediatric cancer should be aware of the complexity of the topic when talking about the cancer experience: while some prefer to talk about the cancer, others find it hard to talk about the emotional impact. As families share their emotions by verbal as well as non-verbal strategies (e.g., physical 
proximity), the creativity of clinicians is challenged, and taking this individuality into account would therefore foster the family adaptation process. Fourth, not talking is important too as its exploration can give access to unvoiced concerns and worries of the family members (Rober, 2002). Moreover, while both the families and the clinicians should respect the silence and even appreciate it as a way to care for each other, clinicians can provide a safe environment where families can try new ways of supporting each other.

\section{Conclusion}

The present study calls for more pediatric cancer research that enhances a family level understanding of the impact of this diagnosis. In these studies, we need to strive to elicit responses from all family members in order to construct a perspective on family practices, such as support giving, that is as complete as possible. Furthermore, clinicians should invite families as a whole in order to best capture family level experiences and must be sensitive to the different needs within the family with regard to cancer-related family communication. 


\section{References}

Alderfer, M.A., Hodges, J., 2010. Supporting siblings of children with cancer: Family-school partnerships. School Mental Health. 2, 72-81.

Alderfer, M. A., Long, K. A., Lown, E. A., Marsland, A. L., Ostrowski, N. L., Hock, J. M., Ewing, L. J., 2010. Psychosocial adjustment of siblings of children with cancer: a systematic review. Psychooncology. 19(8), 789-805.

Alderfer, M. A., Navsaria, N., Kazak, A. E., 2009. Family Functioning and Posttraumatic Stress Disorder in Adolescent Survivors of Childhood Cancer. Journal of Family Psychology. 23, 717-725.

American Cancer Society, 2016. Cancer that develop in children. Retrieved from https://www.cancer.org/cancer/cancer-in-children/types-of-childhood-cancers.html

Brody, A. C., Simmons, L. A., 2007. Family resiliency during childhood cancer: The father's perspective. Journal of Pediatric Oncology Nursing. 24(3), 152-165.

Carr, A., 2012. Family Therapy: Concepts, Process and Practice. Wiley-Blackwell, Hoboken.

Eisikovits, Z., Koren, C., 2010. Approaches to and outcomes of dyadic interview analysis. Qualitative Health Research. 20, 1642-1655.

Fiese, B. H., 1997. Family Context in Pediatric Psychology from a Transactional Perspective: Family Rituals and Stories as Examples. Journal of Pediatric Psychology. 22(2), 183-196.

Hill, C. E., Thompson, B. J. and Nutt-Williams, E., 1997. A guide to conducting consensual qualitative research, Counseling Psychology. 25(4), 517-572.

Kazak, A. E., Barakat, L. P., Alderfer, M., Rourke, M. T., Meeske, K., Gallagher, P. R., Cnaan, A., Stuber, M. L., 2001. Posttraumatic stress in survivors of childhood cancer and mothers: Development and validation of the impact of traumatic stressors interview schedule (ITSIS). Journal of Clinical Psychology in Medical Settings. 8(4), 307-323. 
Kestler, S. A., \& LoBiondo-Wood, G., 2012. Review of symptom experiences in children and adolescents with cancer. Cancer Nursing. 35(2), E31-E49.

Long, K. A., Lehmann, V., Gerhardt, C., Carpenter, A.,Marsland, A., \& Alderfer, M., 2018. Psychosocial Functioning and Risk Factors among Siblings of Children with Cancer: An Updated Systematic Review. Psycho-Oncology. Online First. doi: 10.1002/pon.4669

Morris, S. M., 2001. Joint and individual interviewing in the context of cancer. Qualitative Health Research. 11, 553- 567.

Newman, B. M., Newman, P. R., Griffen, S., O’Connor K, Spas, J., 2007. The relationship of social support to depressive symptoms during the transition to high school. Adolescence. 42, 441-459.

Prchal, A., Landolt, M. A., 2012. How Siblings of Pediatric Cancer Patients Experience the First Time After Diagnosis A Qualitative Study. Cancer Nursing. 35(2), 133-140.

Rimé, B., 2009. Emotion Elicits the Social Sharing of Emotion: Theory and Empirical Review. Emotion Review. 1(1), 60-85.

Rober, P., 2002. Some hypotheses about hesitations and their nonverbal expression in family therapy practice. Journal of Family Therapy. 24, 187-204.

Sloper, P., 2000. Experiences and support needs of siblings of children with cancer. Health \& Social Care in the Community. 8, 298-306.

Smith, J. A., Flowers, P., Larkin, M., 2009. Interpretative Phenomenological Analysis: theory, method and research. Sage Publications, London.

Stegenga, K., Pentz, R. D., Alderfer, M. A., Pelletier, W., Fairclough, D. \& Hinds, P. S., 2018. Child and Parent Access to Transplant Information and Involvement in Treatment Decision Making. Western Journal of Nursing Research. Epub. doi: 10.1177/0193945918770440

Ummel, D., Achille, M., 2016. How not to let secrets out when conducting qualitative research with dyads. Qualitative Health Research. 26(6): 807-815. 
Van Parys, H., Provoost, V., De Sutter, P., Pennings, G., \& Buysse, A., 2017. Multi family member interview studies: a focus on data analysis. Journal of Family Therapy. 39(3), 386-401.

Van Schoors, M., Caes, L., Knoble, N., Goubert, L., Verhofstadt, L. L., Alderfer, M., 2017. Associations between Family Functioning and Child Adjustment after Pediatric Cancer Diagnosis: A Meta-Analysis. Journal of Pediatric Psychology, 42, 6-18.

Van Schoors, M., Caes, L., Verhofstadt, L. L., Goubert, L., Alderfer, M. A., 2015. Systematic Review: Family Resilience After Pediatric Cancer Diagnosis. Journal of Pediatric Psychology, 40, 856868.

Van Schoors, M., De Mol, J., Morren, H., Verhofstadt, L. L., Goubert, L. \& Van Parys, H., 2018. Parents' Perspectives of Changes Within the Family Functioning After a Pediatric Cancer Diagnosis: A Multi Family Member Interview Analysis. Qualitative Health Research, Online First.

Varni, J. W., Katz, E. R., Colegrove, R., Jr., \& Dolgin, M., 1994. Perceived social support and adjustment of children with newly diagnosed cancer. Journal of Developmental and Behavioral Pediatrics. 15(1), 20-26.

Vrijmoet-Wiersma, C. J., van Klink, J. M., Kolk, A. M., Koopman, H. M., Ball, L. M., Egeler, R. M., 2008. Assessment of parental psychological stress in pediatric cancer: A review. Journal of Pediatric Psychology. 33(7), 694-706.

Weber, J., 2011. Individual and Family Stress and Crises. Sage Inc, Thousand Oaks.

Zegaczewski, T. C., K.., Coddington, J.,\& Berg, A. (2015). Factors Related to Healthy Siblings' Psychosocial Adjustment to Children With Cancer: An Integrative Review. Journal of Pediatric Oncology Nursing. 33(3), 218-227. 
Fig. 1 Overarching data analysis strategy

\begin{tabular}{|l|l|}
\hline $\begin{array}{l}\text { Phase I: Interpretative Phenomenological } \\
\text { Analysis (IPA) of all interviews separately: } \\
\text { interview by interview }\end{array}$ \\
$\begin{array}{l}\text { Phase II: Analysis of each family unit: integration } \\
\text { of themes and subthemes of all family members } \\
\text { within the same family }\end{array}$ \\
$\begin{array}{l}\text { Phase III: Cross-family analysis: integration of } \\
\text { process throughout } \\
\text { themes and subthemes of each family (phase II), } \\
\text { resulting in new cross-family thematic categories }\end{array}$ \\
andysis
\end{tabular}


Fig. 2 Main themes and subthemes: a Hierarchical Structure

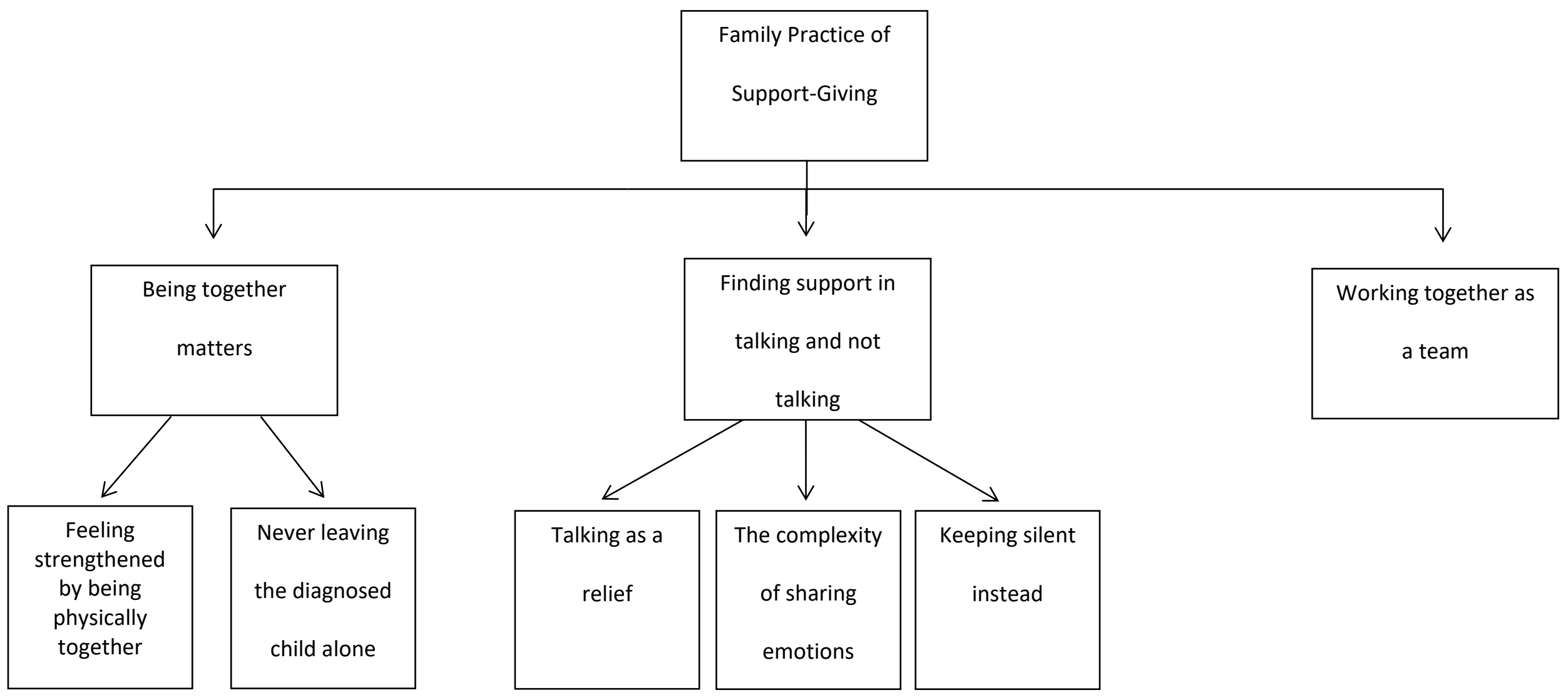

